\title{
A GENERALIZED DYNAMIC MODEL FOR BRUSHLESS DOUBLY-FED INDUCTION MACHINES
}

\author{
S. M. Allam ${ }^{1}$, A. M. Azmy' ${ }^{1}$ M. M. Khater ${ }^{2}$ and M. A. El-Khazendar ${ }^{1}$ \\ 1 Electrical Power and Machines Department, Faculty of Engineering, \\ Tanta University, Tanta, Egypt \\ ${ }^{2}$ Electrical Engineering Department, Faculty of Engineering \\ Minoufiya University, Shebin El-Kom, Egypt
}

\begin{abstract}
This paper presents a detailed dynamic model, by which the dynamic behaviour of Brushless Doubly-Fed Induction Machine (BDFIM) can be successfully predicted. The investigated doublyfed machine has two sets of three-phase stator windings with different pole numbers. The rotor is a squirrel-cage type with a simple modification in order to support the two air-gap rotating fields that are produced by the stator windings and have different pole numbers. The machine model is derived in both natural-machine variables abc-axis and qdo variables axis. The qdo- axis is attached to rotor and hence, it rotates at the rotor speed $\left(\omega_{\mathrm{m}}\right)$. The electromagnetic torque expression is also obtained based on the two presented models. The winding function method is presented as a convenient approach that can be used for machine-winding inductances calculations. Sample case studies are introduced to examine the performance of the proposed model.

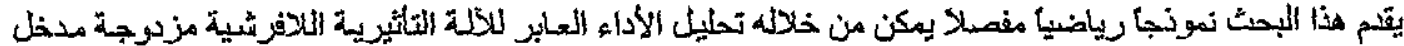

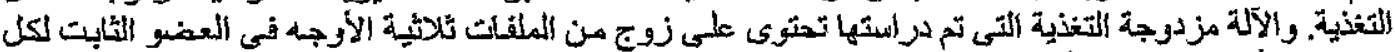

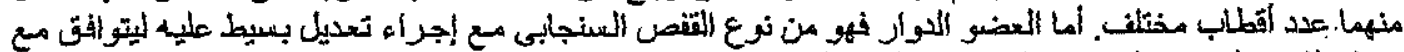

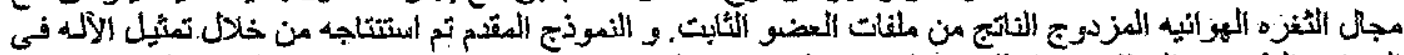

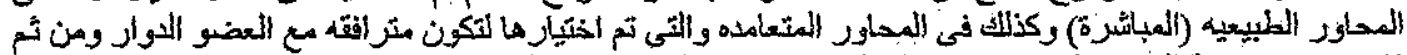

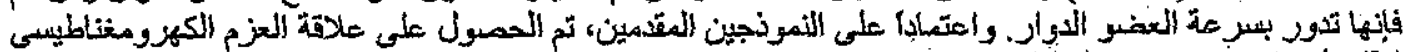

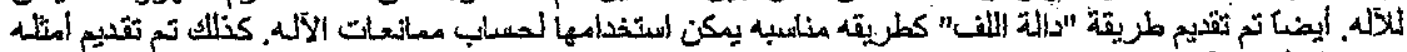

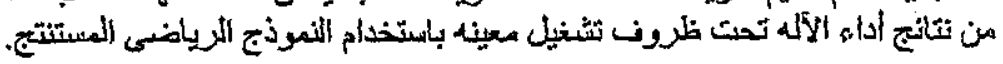

Keywords: Brushless doubly-fed machine- Dynamic modelling-Generalized theory- Induction machine- Self-cascaded, Speed control- Variable speed drives

\section{NOMENCLATURE}

B viscous coefficient

$i_{\text {abck }} \quad 3$-ph currents of either stator windings

$i_{r k i} \quad i^{\text {th }}$-rotor loop current of either rotor circuit

I Rotor inertia

$\mathrm{N}_{k} \quad$ Turns per phase of either stator windings

$\mathrm{p}$ The differential operator " $\mathrm{d} / \mathrm{dt}$ "

$P_{k} \quad$ Pole-pairs of eitlier stator windings

$R \quad$ Rotor radius

$r_{s k} \quad$ Per-phase resistance of either stator windings

$\Gamma_{e m} \quad$ Total electromagnetic developed torque

$\mathrm{T}_{\mathrm{L}} \quad$ Load torque

$V_{\mathrm{abck}}$ 3-ph voltages of either stator windings

$\mu_{0} \quad$ Permeability for vacuum

$\ell \quad$ Rotor axial length

$\hat{\theta}_{\mathrm{m}}$ Rotor mechanical angular position with respect to phase (a) reference axis of the two sets of stator windings

$\theta \quad$ Angular position along the stator inner surface $\mathrm{g}^{-1}\left(\theta_{\mathrm{m}}, \theta\right) \quad$ The inverse air-gap function

$\mathrm{N}_{\mathrm{i}}\left(\theta_{\mathrm{m}}, \theta\right)$ The winding function of winding (i)

$\lambda_{\text {abck }} \quad 3$-ph flux linkages of either stator windings

$L_{\ell \mathrm{k}} \quad$ Leakage inductance of either stator windings

$\mathrm{L}_{\mathrm{mk}} \quad$ Magnetizing inductance of either stator windings

$M_{r} \quad$ Mutual inductance between any two rotor loops

$\mathrm{L}_{\mathrm{mr}} \quad$ Rotor loop magnetizing inductance

$\omega_{m} \quad$ Mechanical rotor speed

$\mathrm{r}_{\mathrm{b}}, \mathrm{L}_{\mathrm{b}}$ Rotor bar resistance and leakage inductance respectively.

$r_{e}, L_{e}$ End ring segment resistance and leakage inductance respectively 


\section{INTRODUCTION}

Squirrel-cage induction motors are the most widely used motors in AC-drive applications. This is attributed to their ruggedness, low cost, and few maintenance requirements. The number of industrial applications, which utilize AC adjustable speed drives (ASDs), is increasing rapidly. The primarily reason for this development is the significant advent of power electronics. The main disadvantage of using singly-fed machines for ASDs is the need for large and expensive power conditioning units that should withstand the full motor power. This increases both the capital cost and the harmonic current pollution of the overall system [1]. The Brushless Doubly-Fed Induction Machines (BDFIMs) shows a great promise in reducing the rating of power electronic converters needed for ASDs application [2]. The BDFIM represents a development of self-cascaded machines with two three-phase stator windings having different number of poles accommodated in a single machine frame. In addition, it is required to introduce a modification to the cage rotor structure [3]-[6].

The two stator windings are referred to as: the power winding, connected directly to the main power supply, and the control windings connected to the main power supply via power electronic converters. In a BDFIM, the rotor structure basically determines the magnetic coupling between the two stator windings, which in turn determines the machine behaviour [6]. BDFIM is a special form of slip recovery machines that reduce the capacity of the required inverter to be used if the required speedcontrol range is limited [1]-[7]. This will lead to a significant reduction in the drive cost. Owing to its brushless property, the BDFIM is mechanically robust and reliable. It is found that the BDFIM has the ability to provide precise speed control and good power factor with reduced converter capacity, as low as $25 \%$ of the machine rating [3]-[4]. This results in a greatly reduced capital cost of the overall system. A further advantage of the BDFIM is derived from the fact that the power electronic converters do not process the bulk power entering or leaving the machine directly.

The dynamic model of Brushless Doubly-Fed Machines (BDFMs) was first presented in [1]. However, the presented model is based on a special configuration of both stator and rotor winding connections. The stator-winding configuration appears to be far more complicated than the threephase winding of a conventional induction or synchronous machine. In addition, a more complex rotor configuration than the conventional cage rotor is used. The dynamic model introduced in [1], has addressed the $3 / 1$ (power winding to control winding pole-pair numbers) exclusively. An extended model, which is appropriate for any number of pole-pairs, was introduced in [2]. However, the structure of the BDFM used is similar to that used in [1]. The main problem of these models is the complicated structure of both stator and rotor windings that these models based upon.

A new model based on a dual stator winding induction machine is presented in [8]. The dual stator machine consists of a conventional squirrel-cage induction motor having two three-phase stator windings wound for two and six poles. The twostator windings are simultaneously fed from two independent variable frequenc ${ }^{\prime}$ power supplies. This results in increasing the capital cost of the overall system and thus, reducing the applications, in which this system can be used.

The aim of this paper is to present a generalized and detailed dynamic model valid for predicting the dynamic performance of BDFIMs under different loading conditions. The proposed modelling process starts by describing all machine equations in its natural yariables abc-axis. Then, the model is transformed to qdo variables axis using appropriate transformation matrices. The machine-winding inductances are calculated using winding function method. In addition, the paper aims at investigating the possibility of simpler structure of the BDFIM than that used before. The investigated BDFIM consists of a simply modified squirrel-cage rotor and a stator with two separate windings wound for a dissimilar number of poles. Each stator winding is fed from an independent power supply. Only one of the two stator windings is fed from a variablefrequency variable-voltage inverter.

\section{SYSTEM DESCRIPTION}

Fig. 1 shows the schematic diagram of the investigated BDFIM. There are two three-phase windings with different number of poles, in order to avoid magnetic mutual coupling, placed in the stator slots [1]. These windings are simultaneously fed from two independent power'supplies and each one produces a separate torque component. One set of stator windings is called the power windings; through which full machine power must pass, and is fed directly from a constant voltage constant frequency power supply. The other set is called the control windings, through which partial controlled power passes, and is fed from a variable voltage variable frequency power supply.

The rotor is a squirrel-cage type with a simple modification in its structure to support the two airgap rotating fields that have $d$ : fferent pole numbers produced by the two-sets of stator windings [6]. In [7], it is stated that the essential requirement for 
brushless doubly-fed machine action is that the frequency and distribution of currents induced in the rotor by the first air-gap field match that induced by the second. The two stator windings will be then coupled via the rotor, even though they have different pole numbers and may be excited at different frequencies. This implies that the number of rotor bars should be equal to the summation of polepair numbers of both stator windings. Thus, the number of rotor bars will be small for any realistic combination of pole-pair numbers [7]:

Such low number of rotor bars results in a very highreferred rotor leakage reactance [7]. Therefore, more work has been done to increase the number of rotor slots and distribute each bar between several slots. The most common practice, by which this can be accomplished is to connect the rotor bars selectively to produce a set of concentric or nested loops. Each nested loop has to be isolated from the others, and the number of nested loops is equal to the required number of rotor bars. As an alternative, the outermost loop of each nest has to form the required number of rotor bars whilst the other loops are joined at a common end ring. These two ways used in rotor bars arrangements are not easily fabricated. Furthermore, the cost of this type of machines is high since both stator and rotor have to be redesigned.

In this paper, a very simple modification in the rotor cage is introduced. The rotor bars is divided into number of groups that equal the required number of rotor bars (summation of pole-pairs of the two-stator windings). Separating each group from the others can be easily done at one side only of the two end rings. This means that one end ring is divided into a number of sections; each connecting a number of bars, while the other end ring connects all rotor bars. It should be noted that this modification in the end ring structure results in zero currents in some rotor loops at which the end ring is separated. For 6-pole and 2-pole stator windings, the number of required rotor bars or groups equals four. Therefore, one side of the end rings should be divided into four groups or sections as shown in Fig. 1.

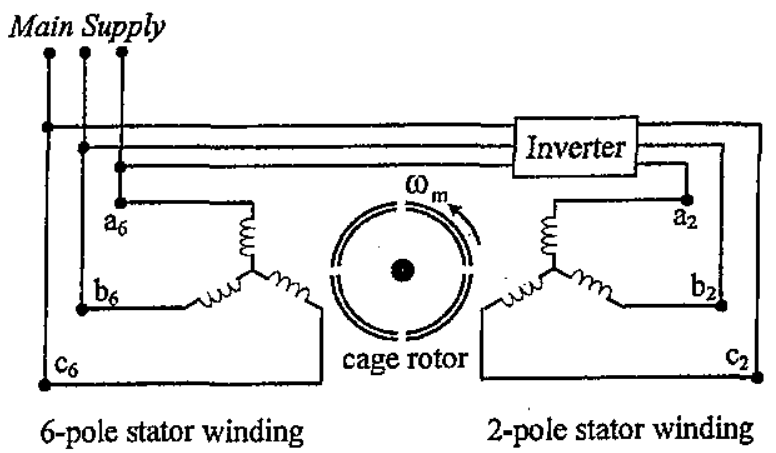

Fig. 1. Schematic diagram of the BDFIM

\section{INDUCTANCE CALCULATIONS}

The machine-winding inductances can be calculated by a particular convenient approach called winding functions method [9]-[10]. The winding function is defined as the spatial distribution of $M M F$ due to a unit current flowing in the winciing. According to this method, the machine inductances are calculated by an integral expression representing the placement of winding turns along the air-gap periphery. This method is particularly convenient for the analysis of unusual machines since it assumes no symmetry in the placement of any motor coil in the slots [10]. According to the winding function theory, the mutual inductance between any two windings (i) and (j) in any machine can be easily computed from the following expression:

$$
\mathrm{L}_{\mathrm{ij}}=\mu_{\mathrm{o}} \mathrm{R} \ell \int_{0}^{2 \pi} \mathrm{g}^{-1}\left(\theta_{\mathrm{m}}, \theta\right) \mathrm{N}_{\mathrm{i}}\left(\theta_{\mathrm{m}}, \theta\right) \mathrm{N}_{\mathrm{j}}\left(\theta_{\mathrm{m}}, \theta\right) \mathrm{d} \theta
$$

\subsection{Stator Winding Function}

Each stator phase is assumed to be sinusoidally wound along the air gap. Hence, the winding function of each one of the two sets of stator windings can be written as:

$$
\begin{aligned}
& \mathrm{N}_{\mathrm{ak}}(\theta)=\left(\mathrm{N}_{\mathrm{k}} / 2 \mathrm{P}_{\mathrm{k}}\right) \cos \left(\mathrm{P}_{\mathrm{k}} \theta\right) \\
& \mathrm{N}_{\mathrm{bk}}(\theta)=\left(\mathrm{N}_{\mathrm{k}} / 2 \mathrm{P}_{\mathrm{k}}\right) \cos \left(\mathrm{P}_{\mathrm{k}} \theta-2 \pi / 3\right) \\
& \mathrm{N}_{\mathrm{ck}}(\theta)=\left(\mathrm{N}_{\mathrm{k}} / 2 \mathrm{P}_{\mathrm{k}}\right) \cos \left(\mathrm{P}_{\mathrm{k}} \theta+2 \pi / 3\right)
\end{aligned}
$$

It should be noted that all equations used for the twostator windings are similar except for their different number of poles, turns per phase, resistance, and inductance. So, instead of writing theses equations twice, the subscript " $\mathrm{k}$ " is used denoting either the power or the control windings. Hence, the same equation can be used to describe the two stator windings just by defining " $k$ " with suitable number related to each one of the two sets of stator windings.

\subsection{Rotor-Loops Winding Function}

Squirrel-cage rotor has " $n$ " identical and equally spaced bars, which are shorted together by the two end-rings. Therefore, it can be modelled as " $n$ " identical magnetically coupled circuits or loops [8]. Each loop encompasses two adjacent rotor bars and the connection portions of the end rings between them. The normalized winding function for the $i^{\text {th }}$. rotor loop is given by the $M M F$ distribution produced by one ampere flowing through this loop. For all other loops, the normalized winding functions are similar, with only difference in the phase angles, which are defined by the position of each loop with respect to the reference point. Fig. 2 shows the normalized winding function for the $\mathrm{i}^{\text {th }}$-rotor loop, which can be written as follows: 


$$
N_{C i}\left(\theta_{i}, \theta\right)=\left\{\begin{array}{cc}
-\alpha_{r} / 2 \pi & 0 \leq \theta \leq \theta_{i} \\
1-\alpha_{r} / 2 \pi & \theta_{i} \leq \theta \leq \theta_{i}+\alpha_{r} \\
-\alpha_{r} / 2 \pi & \theta_{i}+\alpha_{r} \leq \theta \leq 2 \pi
\end{array}\right\}
$$

Where: $\theta_{\mathrm{i}}=\theta_{\mathrm{m}}+(\mathrm{i}-1) \alpha_{\mathrm{r}}$

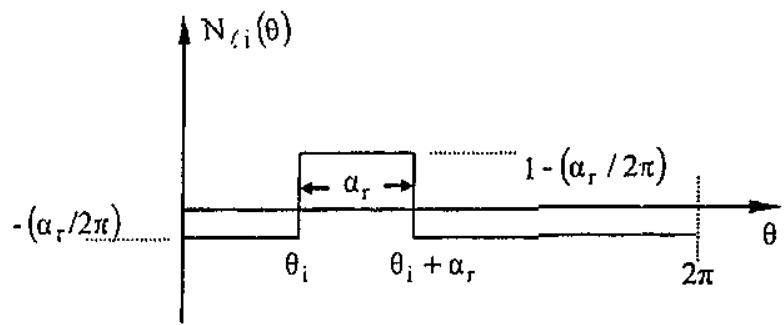

Fig. 2. The $i^{\text {th }}$-rotor loop winding function

\subsection{Inverse Air-Gap Function}

For a conventional squirrel-cage rotor, the air-gap is assumed to be uniform and hence, the inverse air-gap function may be considered to be constant without contribution in the integration shown in (1).

\subsection{Inductance Formulas}

Magnetizing and mutual inductance formulas of both stator windings and n-rotor loops can be easily obtained using (1), (2), and (3). The final expressions or formulas of these inductances are given in the appendix.

\section{DYNAMIC MODEL IN NATURAL MACHINE VARIABLES AXIS}

\subsection{Stator Winding Voltage Equations}

The 3-phase voltage equation of each one of the two stator windings can be written in a matrix form as follows:

$\left[v_{\text {abck }}\right]=\left[r_{s k}\right]\left[i_{\text {abck }}\right]+p\left[\lambda_{\text {abck }}\right]$

It should be noted that in the flux linkage calculations, there is no component of flux linkage of any of the two stator windings due to the current of the other windings. This is attributed to the mutual decoupling of the two stator windings since they have different number of poles. As a result, the rotor can be modelled as two independent circuits. Each one has "n"-rotor loops and is related to one of the two-stator windings. So, the subscript ' $k$ ' may be also used to define the two different rotor circuits related to the corresponding two stator windings. Hence, the flux linkage in each of the stator windings is established due to only two components. The first is due to the stator current in the same windings, and the second is due to the current of the corresponding rotor circuit, which has the same number of poles. The flux linkage can be rewritten as:

$\lambda_{\text {abck }}=\lambda_{\text {abck abck }}+\lambda_{\text {abck rki }}$

Where: $\lambda_{\text {abck abck }}:$ is the flux linkage of any of the two stator windings due to the corresponding current of the same windings, and

$\lambda_{\text {abck rki }}$ : is the flux linkage of any of the stator windings due to $i^{\text {th }}$-rotor loop current of the corresponding rotor circuit.

The total flux linkage for both stator windings can be expanded as:

$\lambda_{\text {abck }}=\left[\mathrm{L}_{\text {abck abck }}\right]\left[\mathrm{i}_{\text {abck }}\right]+\left[\mathrm{L}_{\text {r abck rki }}\right]\left[\mathrm{i}_{\text {rki }}\right]$

Where:

$\left[\mathrm{L}_{\mathrm{abck} a b c k}\right]=\left[\begin{array}{ccc}\mathrm{L}_{\ell \mathrm{k}}+\mathrm{L}_{\mathrm{mk}} & -\mathrm{L}_{\mathrm{mk}} / 2 & -\mathrm{L}_{\mathrm{mk}} / 2 \\ -\mathrm{L}_{\mathrm{mk}} / 2 & \mathrm{~L}_{\mathrm{ck}}+\mathrm{L}_{\mathrm{mk}} & -\mathrm{L}_{\mathrm{mk}} / 2 \\ -\mathrm{L}_{\mathrm{mk}} / 2 & -\mathrm{L}_{\mathrm{mk}} / 2 & \mathrm{~L}_{\iota \mathrm{k}}+\mathrm{L}_{\mathrm{mk}}\end{array}\right]$ , the matrix $\left[\mathrm{L}_{\mathrm{mabck}} \mathrm{rki}\right]$ is given in the appendix,

$\left[i_{\text {rki }}\right]^{T}=\left[\begin{array}{llll}i_{\text {rk1 }} & i_{\text {rk2 }} & \ldots & i_{\text {rkn }}\end{array}\right]$, and

" $n$ " is the total number of scuirrel-cage rotor bars (loops)

It should be noted that each column in the matrix [ $\left.\mathrm{L}_{\mathrm{m} \text { abck rki }}\right]$ corresponds to a certain loop. In addition, each element in the matrix $\left[\mathrm{i}_{\mathrm{rki}}\right]^{\mathrm{T}}$ corresponds to a certain loop. For a standard squirrelcage rotor, without any modification in its structure, all rotor loops represent closec loops through which the rotor loop current can pass. Therefore, the order of the two matrices $\left[\mathrm{L}_{\mathrm{m} \text { abck rki }}\right]$ and $\left[\mathrm{i}_{\mathrm{rki}}\right]^{\mathrm{T}}$ is related to the total number of rotor loops. Thus, the order of these two matrices, for a standard cage rotor, is ' $3{ }^{*} n$ ' and ' $1{ }^{*} \mathrm{n}$ ' respectively. However, for a modified cage rotor, which is presented in this paper and due to the discontinuity of one of the two end rings, some rotor loops represent open loops. For the open loops at which the end ring is separated, the rotor loop current is set to zero and thus, the corresponding columns or elements are eliminated from the two matrices. The number of these columns equals the number of end ring sections (i.e. summation of pole-pairs of both stator windings). This reduces the order of the matrices to be ' $3{ }^{*} \mathrm{~m}$ ' and ' $1{ }^{*} \mathrm{~m}$ ' respectively, where ' $\mathrm{m}$ ' is the total number of closed rotor loops (i.e. difference between total number of rotor bars or loops and open loops at which the end ring is separated). Mathematically " $m$ " can be given by:

$\mathrm{m}=\mathrm{n}-\sum \mathrm{P}_{\mathrm{k}}$, where $\sum \mathrm{P}_{\mathrm{k}}$ is the summation of the pole-pairs of the two stator windings.

These notes can be easily concluded by putting a condition for the subscript " $i$ ", which used in $\left[i_{r k i}\right]^{T}$ matrix as follows:

$$
i=(1,2, \ldots, n), i \neq q n_{p}
$$

Where: 
"q" $=\left(1,2, \ldots, \Sigma \dot{P}_{k}\right)$, and

$" n_{p} "\left(=n / \sum P_{k}\right):$ is the total number of squirrel-cage rotor bars per pole-pair summation of the two-stator windings.

\subsection{Rotor Loops Voltage Equations}

In order to obtain the n-loops rotor voltage equations, the rotor circuit can be divided into two circuits with the same number of poles of the corresponding twostator windings. Fig. 3 shows a schematic diagram of n-rotor loops winding for any of the corresponding two-stator windings just after defining ' $\mathrm{k}$ '. An open circuit rotor loop from one side of end rings is also shown in Fig. 3.

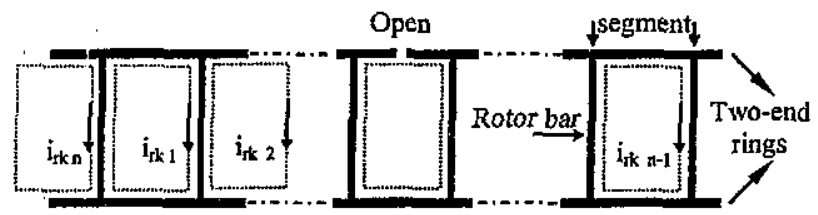

Fig. 3. Rotor loops winding configuration

After assigning ' $\mathrm{k}$ ', it should be noted that the equivalent two rotor circuits have the same loop resistance, loop leakage inductance, loop magnetizing inductance and mutual inductance between any two rotor loops with values equal to that of conventional squirrel-cage rotor. The main difference between the two rotor circuits is the mutual inductance between each rotor circuit itself and the corresponding stator windings. Since the two stator windings are mutually decoupled, the flux linkage in each rotor circuit is created due to only two components: the first is due to the rotor current in the same circuit and the second is due to the current of the corresponding stator winding, which have the same number of poles.

The rotor-loops voltage equation of each one of the two rotor circuit is written in a matrix form as follows:

$[0]=\left[r_{r}\right]\left[i_{r k i}\right]+p\left[\lambda_{r k i}\right]$

Where:

$\left[\mathrm{r}_{\mathrm{r}}\right]=\left[\begin{array}{cccc}\mathrm{r}_{\ell} & -\mathrm{r}_{\mathrm{b}} & \cdots & -\mathrm{r}_{\mathrm{b}} \\ -\mathrm{r}_{\mathrm{b}} & \mathrm{r}_{\ell} & \cdots & 0 \\ \vdots & \vdots & \ddots & \vdots \\ -\mathrm{r}_{\mathrm{b}} & 0 & \cdots & \mathrm{r}_{\ell}\end{array}\right]$ and $\mathrm{r}_{\ell}=2\left(\mathrm{r}_{\mathrm{b}}+\mathrm{r}_{\mathrm{e}}\right)$.

In addition, the corresponding n-rotor loops flux linkage of either rotor circuits can be rewritten as:

$\lambda_{\text {rki }}=\lambda_{\text {rki rkj }}+\lambda_{\text {rki abck }}, j=(1,2, \ldots, \mathrm{n})$

Where: $\lambda_{\text {rkj rkj }}:$ is the $\mathrm{i}^{\text {th }}$-rotor loop flux linkage of eithex rotor circuits due to $n$ - rotor loops current of the same circuit, and

$\lambda_{\text {tki abck }}$ : is the $\mathrm{i}^{\text {th }}$-rotor loop flux linkage of either rotor circuits due to the current of corresponding stator winding.

The total n-rotor loops flux linkage is written in an expanded matrix form as:

$\left[\lambda_{\text {rki }}\right]=\left[\mathrm{L}_{\mathrm{r}}\right]\left[\mathrm{i}_{\mathrm{rki}}\right]+\left[\mathrm{L}_{\mathrm{m} \mathrm{rki} \mathrm{abck}}\right]\left[\mathrm{i}_{\text {abck }}\right]$

Where:

$\left[\mathrm{L}_{\mathrm{r}}\right]=\left[\begin{array}{cccc}\mathrm{L}_{\ell \mathrm{r}}+\mathrm{L}_{\mathrm{mr}} & \mathrm{M}_{\mathrm{r}}-\mathrm{L}_{\mathrm{b}} & \cdots & \mathrm{M}_{\mathrm{r}}-\mathrm{L}_{\mathrm{b}} \\ \mathrm{M}_{\mathrm{r}}-\mathrm{L}_{\mathrm{b}} & \mathrm{L}_{\ell \mathrm{r}}+\mathrm{L}_{m r} & \cdots & \mathrm{M}_{\mathrm{r}} \\ \vdots & \vdots & \ddots & \vdots \\ \mathrm{M}_{\mathrm{r}}-\mathrm{L}_{\mathrm{b}} & \mathrm{M}_{\mathrm{r}} & \cdots & \mathrm{L}_{\ell \mathrm{r}}+\mathrm{L}_{\mathrm{mr}}\end{array}\right]$,
$\mathrm{L}_{\ell \mathrm{r}}=2\left(\mathrm{~L}_{\mathrm{b}}+\mathrm{L}_{\mathrm{e}}\right)$, and $\left[\mathrm{L}_{\mathrm{m} \text { rki abck }}\right]=\left[\mathrm{L}_{\mathrm{m} \text { abck rki }}\right]^{\mathrm{r}}$

5.3. Electromagnetic Developed Torque Equation

The electromagnetic developed torque of a BDFIM can be divided into two components. Each one is due to the mutual coupling between one of the two-stator windings and the corresponding rotor circuit. Thus, the total electromagnetic developed torque is given by the summation of these two components and can be written as:

$\mathrm{T}_{\mathrm{em}}=\sum \mathrm{T}_{\mathrm{emk}}$

Where:

$\left.\mathrm{T}_{\text {emk }}=\left[\mathrm{i}_{\mathrm{abck}}\right]^{\mathrm{T}}\left(\frac{\mathrm{d}}{\mathrm{d} \theta_{\mathrm{m}}}\left[\mathrm{L}_{\mathrm{m} \text { abck rki }}\right]\right) \mathrm{i}_{\mathrm{rki}}\right]$

\subsection{The electromechanical equation}

The electromechanical equation of a BDFIM can be easily written as:

$\mathrm{T}_{\mathrm{em}}=\mathrm{J} * \mathrm{p} \omega_{\mathrm{m}}+\mathrm{B} * \omega_{\mathrm{m}}+\mathrm{T}_{\mathrm{L}}$

Using (4) through (10), the system dynamic performance can be analyzed in natural machine variables axis.

\section{DYNAMIC MODEL IN QDO-AXIS ROTOR REFERENCE FRAME}

The main problem of the previous model, which is derived in natural machine variables axis, is the timevarying mutual inductances. This results in a very complex model. In order to eliminate the timevarying inductances in voltage equations, the previous dynamic model is transformed to qdo-axis. The qdo-axis is fixed in the rotor, which rotates at the rotor speed $\left(\omega_{\mathrm{m}}\right)$. Fig. 4 shows the phase-axis relationship for phase "a" of any of the two stator windings axis and the $\mathrm{n}^{\text {th }}$-rotor loops axis. 


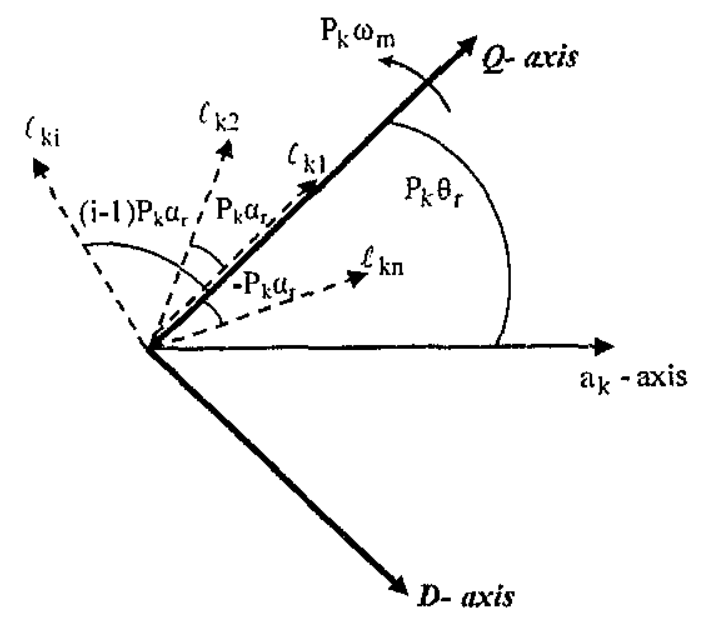

Fig. 4. Phase axis relationship of the BDFIM

\subsection{QDO-Axis Voltage Equations}

\section{A. QDO-Axis Stator Winding Voltage Equations}

Aided with Fig. 4, the transformation matrix of either stator windings ( $a b c_{k}$-axis variables) to the corresponding $\mathrm{qdo}_{k}$-axis variables can be written as follows:

$\left[\mathrm{f}_{\mathrm{qdok}}\right]=\left[\mathrm{k}_{\mathrm{sk}}\right]\left[\mathrm{f}_{\mathrm{abck}}\right]$

Where ' $f$ ' represents either voltage, current or flux linkage, and

$\left[k_{s k}\right]=\frac{2}{3}\left[\begin{array}{ccc}\cos \left(\mathrm{P}_{\mathrm{k}} \theta_{\mathrm{r}}\right) & \cos \left(\mathrm{P}_{\mathrm{k}} \theta_{\mathrm{r}}-\frac{2 \pi}{3}\right) & \cos \left(\mathrm{P}_{\mathrm{k}} \theta_{\mathrm{r}}+\frac{2 \pi}{3}\right) \\ \sin \left(\mathrm{P}_{\mathrm{k}} \theta_{\mathrm{r}}\right) & \sin \left(\mathrm{P}_{\mathrm{k}} \theta_{\mathrm{r}}-\frac{2 \pi}{3}\right) & \sin \left(\mathrm{P}_{\mathrm{k}} \theta_{\mathrm{r}}+\frac{2 \pi}{3}\right) \\ \frac{1}{2} & \frac{1}{2} & \frac{1}{2}\end{array}\right]$

Where $\theta_{r}=\theta_{m}+\delta$, and $\delta=\alpha_{r} / 2$

The inverse of this transformation matrix that transforms the $q_{d o_{k}-}$ axis variables to either stator winding $a b c_{k}$ - axis variables is given by:

$\left[f_{\text {abck }}\right]=\left[k_{\text {sk }}\right]^{-1}\left[f_{\text {qdok }}\right]$

Where:

$\left[k_{s k}\right]^{-1}=\left[\begin{array}{ccc}\cos \left(\mathrm{P}_{\mathrm{k}} \theta_{\mathrm{r}}\right) & \sin \left(\mathrm{P}_{\mathrm{k}} \theta_{\mathrm{r}}\right) & 1 \\ \cos \left(\mathrm{P}_{\mathrm{k}} \theta_{\mathrm{r}}-\frac{2 \pi}{3}\right) & \sin \left(\mathrm{P}_{\mathrm{k}} \theta_{\mathrm{r}}-\frac{2 \pi}{3}\right) & 1 \\ \cos \left(\mathrm{P}_{\mathrm{k}} \theta_{\mathrm{r}}+\frac{2 \pi}{3}\right) & \sin \left(\mathrm{P}_{\mathrm{k}} \theta_{\mathrm{r}}+\frac{2 \pi}{3}\right) & 1\end{array}\right]$

Applying the transformation matrix and its inverse to (4), results in the representation of the stator voltage equation in the qdo $\mathrm{q}_{\mathrm{k}}$-axis. The final $\mathrm{qdo}_{\mathrm{k}}$-axis stator voltage equation can be written in a matrix form as:

$\left[v_{\text {qdok }}\right]=\left[r_{s k}\right]\left[i_{\text {qdok }}\right]+p\left[\lambda_{\text {qdok }}\right]+\omega_{k}\left[\lambda_{\text {qdok }}\right]$

Where: $\left[\mathrm{r}_{\mathrm{sk}}\right]=\left[\begin{array}{ccc}\mathrm{r}_{\mathrm{sk}} & 0 & 0 \\ 0 & \mathrm{r}_{\mathrm{sk}} & 0 \\ 0 & 0 & \mathrm{r}_{\mathrm{sk}}\end{array}\right]$, and $\left[\omega_{\mathrm{k}}\right]=\mathrm{P}_{\mathrm{k}}\left[\begin{array}{ccc}0 & \omega_{\mathrm{m}} & 0 \\ -\omega_{\mathrm{m}} & 0 & 0 \\ 0 & 0 & 0\end{array}\right]$

\section{B. QDO-Axis Rotor Loops Voltage Equations}

The transformation matrix of either rotor circuits of n-rotor loops axis to the corresponding $\mathrm{qdo}_{\mathrm{rk}}$-axis variables can be written based on Fig. 4 as:

$\left[\mathrm{f}_{\text {qdork }}\right]=\left[\mathrm{k}_{\mathrm{rk}}\right]\left[\mathrm{f}_{\mathrm{rki}}\right]$

Where:

$\left[k_{r k}\right]=\frac{2}{m}\left[\begin{array}{cccc}\cos (0) & \cos \left(P_{k} \alpha_{r}\right) & \cdots & \cos \left((n-1) P_{k} \alpha_{r}\right) \\ -\sin (0) & -\sin \left(P_{k} \alpha_{r}\right) & \cdots & -\sin \left((n-1) P_{k} \alpha_{r}\right) \\ \frac{1}{2} & \frac{1}{2} & \cdots & \frac{1}{2}\end{array}\right]$

The back transformation matrix of qdo $_{\mathrm{rk}}$-axis to the corresponding rotor circuits of $n$-rotor loops winding axis is given by:

$\left[f_{r k i}\right]=\left[k_{\text {rk back }}\right]\left[f_{\text {qdork }}\right]$

Where:

$\left[k_{\text {rk back }}\right]=\left[\begin{array}{ccc}\cos (0) & -\sin (0) & 1 \\ \cos \left(P_{k} \alpha_{r}\right) & -\sin \left(P_{k} \alpha_{r}\right) & 1 \\ \vdots & \vdots & \vdots \\ \cos \left((n-1) P_{k} \alpha_{r}\right) & -\sin \left((n-1) P_{k} \alpha_{r}\right) & 1\end{array}\right]$

It should be noted that the absence of some columns in the $\left[i_{\text {rki }}{ }^{\Gamma}\right.$ matrix, corresponding to open rotor loops, necessitates the absence of corresponding columns in the transformation matrix $\left[\mathrm{k}_{\mathrm{rk}}\right]$ and rows in the back transformation matrix $\left[k_{\mathrm{rk} \text { back }}\right]$. In addition, the number of these absent columns or rows is equal to summation of pole-pairs of both stator windings.

Appling the transformation matrix and the back transformation matrix to (6) results in $\mathrm{qdo}_{\mathrm{rk}}$-axis rotor voltage equation. The final $q \mathrm{do}_{\mathrm{r}}$-axis rotor voltage equation can be written in a matrix form as:

$0=\left[r_{q d o r k}\right]\left[i_{q d o ~ r k}\right]+p\left[\lambda_{\text {qdo rk }}\right]$

Where: $r_{\mathrm{qdo} \mathrm{rk}}=\left[\begin{array}{ccc}\mathrm{r}_{\mathrm{rk}} & 0 & 0 \\ 0 & \mathrm{r}_{\mathrm{rk}} & 0 \\ 0 & 0 & \mathrm{r}_{\mathrm{O}}\end{array}\right]$

$\mathrm{r}_{\mathrm{rk}}=\mathrm{r}_{\ell}-2 \mathrm{r}_{\mathrm{b}}\left(1-\sum \mathrm{P}_{\mathrm{k}} / \mathrm{m}\right) \cos \left(\mathrm{P}_{\mathrm{k}} \alpha_{\mathrm{r}}\right)$

$r_{\text {or }}=\left(r_{\ell}-2 r_{b}\right)$

\subsection{QDO-Axis Flux Linkage Relations}

Appling the transformation matrix and its inverse to the flux linkage equations of both stator windings 
and the corresponding rotor circuits results in the final qdo-axis flux linkage relations.

\section{A. QDO-Axis Stator Flux Linkage Relations}

The total qdo $_{\mathrm{k}}$-axis equation of the stator flux linkage can be written as:

$\lambda_{\text {qdok }}=\lambda_{\text {qdok qdok }}+\lambda_{\text {qdok qdork }}$

Where:

$\lambda_{\text {qdok qdok }}$ : is the qdo $_{\mathrm{k}}$-axis flux linkage of either stator winding due to the corresponding $\mathrm{qdo}_{\mathrm{k}}$-axis stator winding current, and

$\lambda_{\text {qdok qdork }}:$ is the $\mathrm{qdo}_{\mathrm{k}}$-axis flux linkage of either stator winding due to the corresponding $\mathrm{qdo}_{\mathrm{rk}}$-axis rotor current.

The $\mathrm{qdo}_{\mathrm{k}}$-axis stator flux linkage due to the corresponding $\mathrm{qdo}_{\mathrm{k}}$-axis stator winding current is given by:

$\left[\lambda_{\text {qdok qdok }}\right]=\left[\mathrm{L}_{\text {qdok qdok }}\right]\left[\dot{\mathrm{i}}_{\mathrm{qdok}}\right]$

Where:

$\left[\mathrm{L}_{\text {qdok qdok }}\right]=\left[\begin{array}{ccc}\mathrm{L}_{s k} & 0 & 0 \\ 0 & \mathrm{~L}_{s k} & 0 \\ 0 & 0 & \mathrm{~L}_{\ell \mathrm{k}}\end{array}\right], \mathrm{L}_{\mathrm{sk}}=\mathrm{L}_{\ell \mathrm{k}}+\frac{3}{2} \mathrm{~L}_{\mathrm{tnk}}$

The $\mathrm{qdo}_{\mathrm{k}}$-axis stator flux linkage due to the corresponding $\mathrm{qdo}_{\mathrm{rk}}$-axis rotor current is given by:

$\left[\lambda_{\text {qdok qdork }}\right]=\left[L_{\text {m qdok qdork }}\right]\left[\dot{i}_{\text {qdork }}\right]$

Where:

$\left[\mathrm{L}_{\mathrm{m} \text { qdok qdork }}\right]=\left[\begin{array}{ccc}\mathrm{L}_{\mathrm{mkr}} & 0 & 0 \\ 0 & \mathrm{~L}_{\mathrm{mkr}} & 0 \\ 0 & 0 & 0\end{array}\right]$

$\mathrm{L}_{\mathrm{mkr}}=(\mathrm{m} / 2) \mathrm{M}_{\mathrm{kr}}$, and $\mathrm{M}_{\mathrm{kr}}$ is given in the appendix

\section{B. QDO-Axis Rotor Loops Flux Linkage Relations}

The total $\mathrm{qdo}_{\mathrm{rk}}$-axis rotor flux linkage equation can be written as:

$\lambda_{\text {qdork }}=\lambda_{\text {qdork qdork }}+\lambda_{\text {qdork qdok }}$

Where:

$\lambda_{\text {qdork qdork }}$ : is the $q \mathrm{do}_{t k}$-axis flux linkage of either rotor circuit due to the corresponding $\mathrm{qdo}_{\mathrm{zk}}$-axis rotor current, and

$\lambda_{\text {qdork qdok }}$ : is the $\mathrm{qdo}_{\mathrm{rk}}$-axis flux linkage of either rotor circuit due to the corresponding $\mathrm{qdo}_{\mathrm{k}}$-axis stator current.

The $\mathrm{qdo}_{\mathrm{sk}}$ axis rotor flux linkage due to the corresponding $\mathrm{qdo}_{\mathrm{rk}}$-axis rotor current is given by:

$\left[\lambda_{\text {qdork qdork }}\right]=\left[\mathrm{L}_{\mathrm{qdo} \mathrm{rk}}\right]\left[\mathrm{i}_{\mathrm{qdork}}\right]$
Where: $\mathrm{L}_{\mathrm{qdo} \mathrm{tk}}=\left[\begin{array}{ccc}\mathrm{L}_{\mathrm{rk}} & 0 & 0 \\ 0 & \mathrm{~L}_{\mathrm{rk}} & 0 \\ 0 & 0 & \mathrm{~L}_{\mathrm{or}}\end{array}\right]$

$\mathrm{L}_{\mathrm{tk}}=\mathrm{L}_{\ell \mathrm{r}}+\mathrm{L}_{\mathrm{mr}}-\mathrm{M}_{\mathrm{r}}-2 \mathrm{~L}_{\mathrm{b}}\left(1-\sum \mathrm{P}_{\mathrm{k}} / \mathrm{rn}\right) \cos \left(\mathrm{P}_{\mathrm{k}} \alpha_{\mathrm{r}}\right)$

$\mathrm{L}_{\mathrm{or}}=\mathrm{L}_{\ell \mathrm{r}}+\mathrm{L}_{\mathrm{mr}}+(\mathrm{n}-1) \mathrm{M}_{\mathrm{r}}-2 \mathrm{~L}_{\mathrm{b}}$

The $\mathrm{qdo}_{\mathrm{rk}}$-axis rotor flux linkage due to the corresponding $\mathrm{qdo}_{\mathrm{k}}$-axis stator winding current is given by:

$\left[\lambda_{\text {qdork qdok }}\right]=\left[L_{\text {m qdork qdok }}\right]\left[\mathbf{i}_{\text {qdok }}\right]$

Where:

$$
\begin{aligned}
& {\left[\mathrm{L}_{\mathrm{m} \text { qdork qdok }}\right]=\left[\begin{array}{ccc}
\mathrm{L}_{\mathrm{mrk}} & 0 & 0 \\
0 & \mathrm{~L}_{\mathrm{mrk}} & 0 \\
0 & 0 & 0
\end{array}\right] \text {, and }} \\
& \mathrm{L}_{\mathrm{mrk}}=(3 / 2) \mathrm{M}_{\mathrm{kr}}
\end{aligned}
$$

The final form of qdo-axis system model in the rotor reference frame is given in the appendix

\subsection{Electromagnetic Torque in terms of QDO- Axis currents}

It is convenient to describe the developed electromagnetic torque from both stator windings as a function of qdo-axis currents. This can be easily obtained after applying the transformation matrices given in (12) and (15) to (9). This yield;

$\mathrm{T}_{\mathrm{emk}}=\left[\mathrm{k}_{\mathrm{sk}}\right]^{-1}\left[\mathrm{i}_{\mathrm{q} d o k}\right] \mathrm{r}\left(\frac{\mathrm{d}}{\mathrm{d} \theta_{\mathrm{m}}}\left[\mathrm{L}_{\mathrm{mabck} r k i}\right]\right)\left[\mathrm{k}_{r \mathrm{k} \text { back }}\right]\left[\mathrm{i}_{q d o r k}\right]$

The final expression of the total electromagnetic developed torque corresponding to qdo-axis currents can be given by:

$\mathrm{T}_{\mathrm{em}}=\Sigma \mathrm{T}_{\mathrm{emk}}=\mathrm{T}_{\mathrm{k} 1}+\mathrm{T}_{\mathrm{k} 2}$

Where:

$$
\begin{aligned}
& \mathrm{T}_{\mathrm{k} 1}=(3 / 2) \mathrm{L}_{\mathrm{mkr}} \mathrm{P}_{\mathrm{k}} \mathrm{i}_{\mathrm{qk}} \mathrm{i}_{\mathrm{drk}} \\
& \mathrm{T}_{\mathrm{k} 2}=(-3 / 2) \mathrm{L}_{\mathrm{mkr}} \mathrm{P}_{\mathrm{k}} \mathrm{i}_{\mathrm{dk}} \mathrm{i}_{\mathrm{qrk}}
\end{aligned}
$$

Equations (10) and (13) through (21) provide a useful dynamic representation of the machine. Thus, this model can be used to describe the dynamic performance of the machine in the qdo rotating axis.

\section{SAMPLE CASE STUDIES}

A sample case study is presented using the proposed model. The presented samples of the simulation results are obtained using the calculated parameters of an actual set-up system. The stator and the rotor of a conventional three-phase squirrel-cage induction motor, rated at $1.1 \mathrm{~kW}, 460 \mathrm{~V}$ and 4-poles, are modified to fit the nature of BDFIM. The original stator winding is replaced by two sets of three-phase windings having different number of poles. One set 
of the two stator windings, the power windings, has six poles, while the other, the control windings, has two-poles. One side of the two-end rings of the rotor is separated to a number of sections that equals the summation of pole-pairs of both stator windings. All mutual and magnetizing inductances are calculated using winding function method. Stator resistance and leakage inductance are measured using standard techniques that used for the conventional induction machines. Dimensions of both rotor bar and end-ring are used to calculate their resistance and leakage inductance.

In this section of the paper, only two samples of different mode of operations are simulated and presented using the proposed model. Simulation results are obtained using Matlab/Simulink software. This paper does not aim to discuss or analyse the presented results. Instead, it presents sample results to confirm the presented model in different modes of operation.

\subsection{Singly-Fed Operation}

Fig. 5 shows the run-up response of the machine for a singly fed mode. In this mode of operation, the power winding is connected to the main supply while the control winding is left open. First, the power winding started with no-load until 0.5 second where a $0.75 \mathrm{~N} . \mathrm{m}$ load torque is applied. The machine gives response similar to that of the conventional induction machine. Thus, the obtained behaviour confirms that the proposed model is valid to describe the transient behaviour of conventional induction machine operating with only one stator winding.
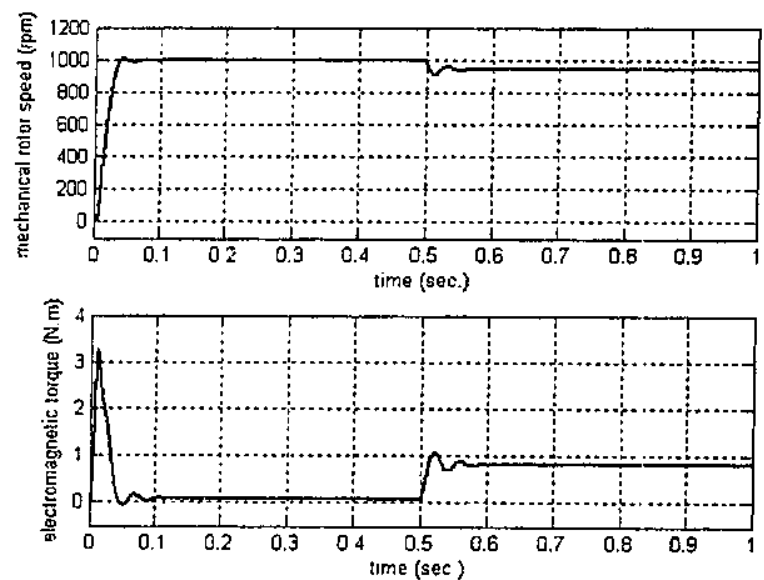

Fig. 5. Run-up response of a singly fed mode of a BDFIM

\subsection{Doubly-Fed Operation}

Fig. 6 shows the run-up response of a doubly- fed mode of a BDFIM under no-load condition. First, the power winding is connected to the main supply while the control winding is left open until 0.5 second.
Then, the control winding is connected to the main supply via an inverter. In Fig. $(\mathrm{a}$, the control winding is excited with the same seijuence of the power winding, while in Fig. 6b, the control winding is excited with the reverse secuence of the power winding.
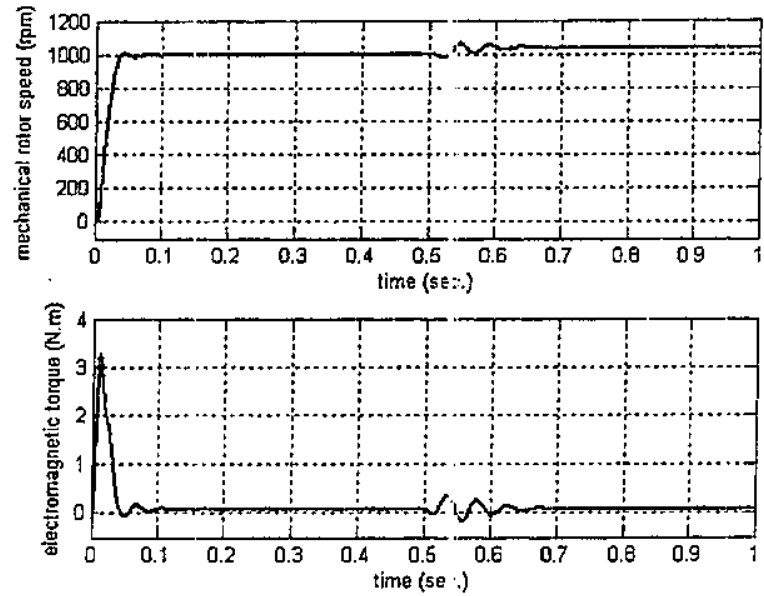

(a) Control winding is excited w; th the same sequence
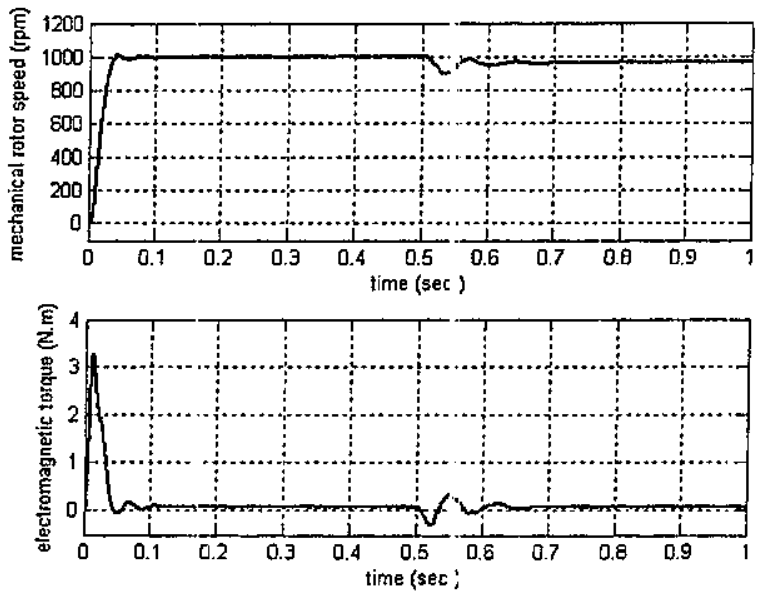

(b) Control winding is excited will a reverse sequence

Fig. 6. Run-up response of a doubly fed mode of a BDFIM

\section{CONCLUSIONS}

This paper has presented a detailed and accurate analysis that is valid for precicting the dynamic performance of brushless dcubly-fed induction machines. A detailed dynamic model in both natural machine variables axis and qdo-axis has been derived from the basic relations of the michine. The winding function method has been introduced as a viable method that can be used for calculating the machine inductances. In order to confirm the validity of the proposed model, Sample case studies have been introduced using actual experimental set-up parameters. 


\section{REFERENCES}

[1] R. Li, A. K. Wallace, R. Spee, and Y. Wang, "Two-axis model development of cage-rotor brushless doubly-fed machines," IEEE Transaction on Energy Conversion, Vol. 6, No. 3, September 1991, pp. 453-460.

[2] M. S. Boger, A. K. Wallace, R. Spee, and R. Li, "General pole number model of the brushless doubly-fed machines," IEEE Transaction on Industry Application, Vol. 31, No. 5, September /October 1995, pp. 1022-1028.

[3] M. S. Boger, A. K. Wallace, R. Spee, and R. Li, "Investigation of appropriate pole number combination for brushless doubly-fed machines applied to pump drives," IEEE Transaction on Industry Application, Vol. 32, No. 1, January/February 1996, pp. 189-194.

[4] M. S. Boger, and A. K. Wallace, "Performance capability analysis of the brushless doubly-fed machine as a wind generator," Seventh International Conference on Electrical Machines and Drives, 11-13 September 1995, No. 412, pp. 458-461.

[5] P. Zaiping, Z. Yanfeng, and M. H. Nagrial, "Review and future application of brushless doubly-fed machine," The 1998 International Conference on Communication, Computer \& Power, Muscat December 7-10, 1998, pp. 306311.

[6] F. Wang, F. Zhang, and L. Xu, "Parameter and performance comparison of brushless machines with cge and reluctance rotors," IEEE Transaction on Industry Application, Vol. 38, No. 5, September /October 2002, pp. 12371243.

[7] S. Williamson, A. C. Ferreira, and A. K. Wallace, "Generalized theory of the brushless doubly-fed machine. Part 1: Analysis," IEE Proc.-Electr. Power Appli., Vol. 144, No. 2, March 1997, pp. 111-122.

[8] A. R. Munoz, and T. A. Lipo, "Dual Stator Winding Induction Machine Drive," IEEE Transaction on Industry Applications," Vol. 36,
No. 5, September/October 2000, pp. 13691379.

[9] F. liang, L. Xu, and T. A. Lipo, "d-q analysis of a variable speed doubly ac excited reluctance motor," Electrical Machines and Power Systems, Vol. 19, No. 2, Mar. 1991, pp. 125138.

[10] L. Xu, F. liang, and T. A. Lipo, "Transient model of a doubly excited reluctance motor," IEEE Transaction on Energy Conversion, Vol. 6, No. 1, March 1991, pp. 126-133.

\section{APPENDIX}

A. Magnetizing inductance of each phase of any of the two stator windings

$$
\mathrm{L}_{\mathrm{m} \text { abck }}=\mathrm{L}_{\mathrm{mk}}=\mu_{\mathrm{o}} \mathrm{R} \ell \mathrm{g}^{-1} \pi\left(\mathrm{N}_{\mathrm{k}} / 2 \mathrm{P}_{\mathrm{k}}\right)^{2}
$$

B. Mutual inductance between phases of any of the two stator windings

$$
\mathrm{L}_{\text {abck bcak }}=-\mathrm{L}_{\mathrm{mk}} / 2
$$

C. Mutual inductance between the two stator windings having different pole number (6-pole and 2-pole as an example)

$\mathrm{L}_{\mathrm{m} \text { abc6 } \mathrm{abc2}}=0$

D. Mutual inductance between any of the two stator windings and the corresponding $n$-rotor loops circuit

$$
\begin{aligned}
& \mathrm{L}_{\mathrm{makrki}}=\mathrm{M}_{\mathrm{kr}} \cos \mathrm{P}_{\mathrm{k}}\left(\theta_{\mathrm{m}}+(\mathrm{i}-1) \alpha_{\mathrm{r}}+\delta\right) \\
& \mathrm{L}_{\mathrm{m} \mathrm{kk} \mathrm{rki}}=\mathrm{M}_{\mathrm{kr}} \cos \left(\mathrm{P}_{\mathrm{k}}\left(\theta_{\mathrm{m}}+(\mathrm{i}-1) \alpha_{\mathrm{r}}+\delta\right)-2 \pi / 3\right) \\
& \mathrm{L}_{\mathrm{mck} \mathrm{rki}}=\mathrm{M}_{\mathrm{kr}} \cos \left(\mathrm{P}_{\mathrm{k}}\left(\theta_{\mathrm{m}}+(\mathrm{i}-1) \alpha_{\mathrm{r}}+\delta\right)+2 \pi / 3\right) \\
& \text { Where: } \delta=\alpha_{\mathrm{r}} / 2, \text { and } \\
& \mathrm{M}_{\mathrm{kr}}=\mu_{\mathrm{o}} \mathrm{R \ell} \mathrm{g}^{-1}\left(\mathrm{~N}_{\mathrm{k}} /\left(\mathrm{P}_{\mathrm{k}}\right)^{2}\right) \sin \left(\mathrm{P}_{\mathrm{k}} \delta\right)
\end{aligned}
$$

E. Magnetizing inductance of each loop

$$
\mathrm{L}_{\mathrm{m} \mathrm{ri}}=\mathrm{L}_{\mathrm{mr}}=\mu_{\mathrm{o}} \mathrm{R} \ell \mathrm{g}^{-1} \alpha_{\mathrm{r}}\left(1-\alpha_{\mathrm{r}} / 2 \pi\right)
$$

F. Mutual inductance between any two rotor loops $(i, j)$

$$
\mathrm{L}_{\mathrm{m} \text { ri } \mathrm{rj}}=\mathrm{M}_{\mathrm{r}}=\mu_{0} \operatorname{R\ell g}^{-1}\left(-\alpha_{\mathrm{r}}^{2} / 2 \pi\right)
$$

G. Mutual inductance between any n-rotor loop circuits and the corresponding stator windings,

$\mathrm{L}_{\mathrm{m} \text { rki ak }}=\mathrm{L}_{\mathrm{m} \text { ak rki }}$

H. The matrix $\left[\mathrm{L}_{\mathrm{m} \text { abck rki }}\right]$ described in section (5.1)

$$
L_{\text {mabck rki }}=M_{k r}\left[\begin{array}{cccc}
\cos \left(P_{k}\left(\theta_{m}+\delta\right)\right. & \cos \left(P_{k}\left(\theta_{m}+\delta+\alpha_{r}\right)\right) & \ldots & \cos \left(P_{k}\left(\theta_{m}+\delta+(n-1) \alpha_{r}\right)\right) \\
\cos \left(P_{k}\left(\theta_{m}+\delta\right)-\frac{2 \pi}{3}\right) & \cos \left(P_{k}\left(\theta_{m}+\delta+\alpha_{r}\right)-\frac{2 \pi}{3}\right) & \ldots & \cos \left(P_{k}\left(\theta_{m}+\delta+(n-1) \alpha_{r}\right)-\frac{2 \pi}{3}\right) \\
\cos \left(P_{k}\left(\theta_{m}+\delta\right)+\frac{2 \pi}{3}\right) & \cos \left(P_{k}\left(\theta_{m}+\delta+\alpha_{r}\right)+\frac{2 \pi}{3}\right) & \ldots & \cos \left(P_{k}\left(\theta_{m}+\delta+(n-1) \alpha_{r}\right)+\frac{2 \pi}{3}\right)
\end{array}\right]
$$


1. Final form of qdo-axis system model in rotor reference frame

$\left[\begin{array}{c}v_{q k} \\ v_{d k} \\ v_{o k} \\ v_{q r k} \\ v_{d r k} \\ v_{\text {ork }}\end{array}\right]=\left[\begin{array}{cccccc}r_{s k}+L_{s k} p & P_{k} \omega_{m} L_{s k} & 0 & L_{m k r} p & P_{k} \omega_{m} L_{m k r} & 0 \\ -P_{k} \omega_{m} L_{s k} & r_{s k}+L_{s k} p & 0 & -P_{k} \omega_{m} L_{m k r} & L_{m k r} p & 0 \\ 0 & 0 & r_{s k}+L_{f k} p & 0 & 0 & 0 \\ L_{m r k} p & 0 & 0 & r_{r k}+L_{r k} p & 0 & 0 \\ 0 & L_{\text {mrk }} p & 0 & 0 & r_{r k}+L_{r k} p & 0 \\ 0 & 0 & 0 & 0 & 0 & r_{\text {or }}+i_{\text {ork }} p\end{array}\right]\left[\begin{array}{c}i_{q k} \\ i_{d k} \\ i_{\text {ok }} \\ i_{\text {qrk }} \\ i_{\text {drk }} \\ i_{\text {ork }}\end{array}\right]$

